\title{
Independent Innovation Ability and Industrial Chain Expanding Policies to Firms in Liaoning Province
}

\author{
Lin $\mathrm{Lu}$ \\ School of Management, Dalian University of Technology \\ No.2 Ling Gong Road, Gan Jingzi District, Dalian116024, China \\ E-mail: lulin@dl.gov.cn \\ Yanying Chen \\ Department of Economics, Dalian University of Technology \\ No.2 Ling Gong Road, Gan Jingzi District, Dalian116024, China \\ Tel: 86-411-8470-7221_E-mail: yychen@dlut.edu.cn \\ Binbin Jiang \\ Department of Economics, Dalian University of Technology \\ No.2 Ling Gong Road, Gan Jingzi District, Dalian116024, China \\ Tel: 86-411-8470-0480 E-mail: blueberry1029@126.com
}

\begin{abstract}
After defining industrial chain and its expanding, we analyze the influencing mechanism of industrial chain expanding to firms' independent innovation ability in this paper, and then we discuss how to enhance firms' independent innovation ability through industrial chain expanding. With regard to the actual and specific conditions of industrial chain and innovation system of firms in Liaoning province, we put forward the patterns and ways for expanding of industrial chain of firms in Liaoning Province and the cultivation of their independent innovation ability.
\end{abstract}

Keywords: Industrial chain, Expanding, Independent innovation ability

\section{Introduction}

The independent innovation ability is closely related to the national strategic benefits and safety, and become the drive of the development of economy. Bettina Von Stamen summarized the factors that had an effect on innovation ability and the ways to foster the firms' innovation ability in his paper ${ }^{[1]}$. Yiming Wang, Jun Wang analyzed the interior and exterior factors which could influence the advancement of firms' independent innovation ability in China ${ }^{[2]}$. In recent years, firms in Liaoning Province are facing various kinds of problems in promoting their innovation abilities, such as low innovation inputs, backwardness of innovation system and lack of ability and activeness in independent innovation. It is the problems that mentioned above influence the sustainable development of Liaoning's economy. From this aspect, the enhancement of independent innovation ability is the problem that urgently needs to be solved. Current researches related to firms' innovation ability always concentrate on the necessity, actual situation and deficiencies. And there are also researches on the influencing factors in innovation of a certain kind firms, but few on the cultivation of independent innovation ability from the expanding of industrial chain. In this paper, we firstly define industrial chain and then introduce the patterns of industrial chain expanding in the next section. In the fourth section we analyze the influencing mechanism of industrial chain expanding to innovation ability. At last conclusion is made, and we also propose some policy suggestions and expectations.

\section{Definition of industrial chain and its expanding}

\subsection{Definition of industrial chain}

Industrial chain is a set of economic activities specific to a certain series of interrelated products or service, from resources collection, product manufacturing, and marketing to final consumption. The structure of industrial chain is the inside division structure of industry ${ }^{[3]}$. The market mechanism broadens and lengthens the industrial chain, and it also 
specializes in the industrial division and updates the structural formation of industrial chain. The link that connects the upstream and downstream firms in the industrial chain is the input-output of products; output of the upstream firms is the input of downstream firms. The product-oriented operation mechanism makes the product form of industrial chain the best way to solve actual situations as industrial chain integration, expanding and risk controls.

Figure1 shows a simple chain of steel industry. The mining firms in the chain provide the raw material of iron ore to the casting and smelting firms, which take the separating the mineral, sintering, coking, steel-making and rolling processes according to their own process flows, and then the outputs are used by the automobile and machinery firms to produce the final products for customers. The outputs of casting and smelting firms could also be used in pipeline and tube firms to satisfy the deep demands of customers with further processing. In the production process, coal, electricity and gasoline firms serve the chain with energy resources and the transportation firms provide transportation services, although these processes taken by coal, electricity, and gasoline and transportation firms don't form tangible products, they play an important role in keeping the industrial chain run smoothly.

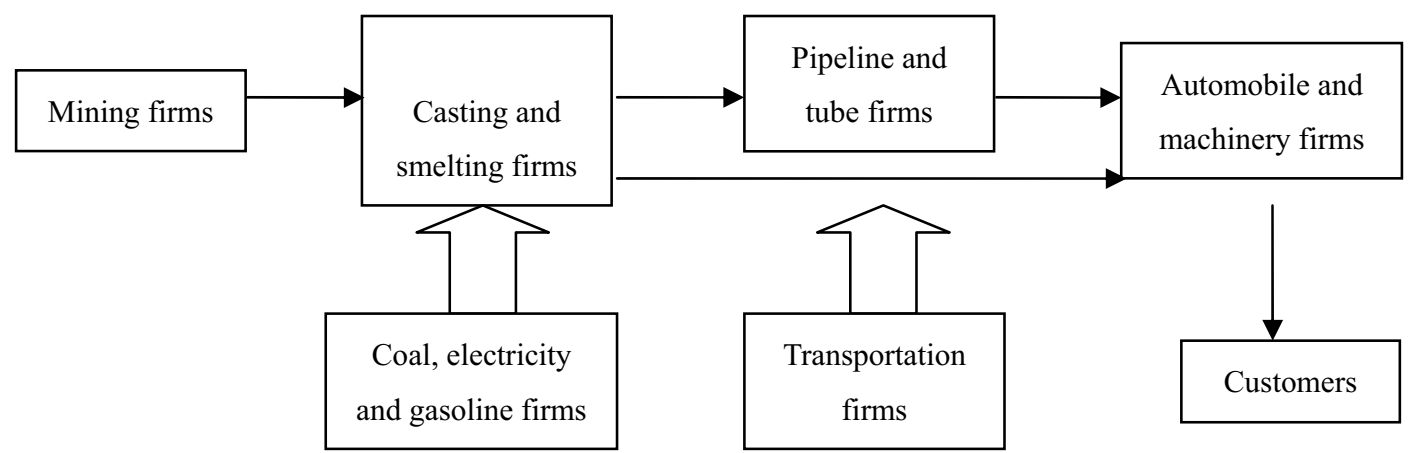

Figure 1. The Industrial Chain of Steel Industry

\subsection{Patterns of industrial chain expanding}

The industrial chain expanding is a process in which enterprise groups of leading industry and corresponding industrial structure forms. Striving for their own competitive advantages, firms reallocate the agent of production under the industrial development rules. The industrial chain expanding could be divided into three categories, horizontal expanding, and vertical expanding and integrated expanding.

Horizontal expanding refers to cooperation, merge or recompose in a certain part of the industrial chain so as to raise the concentration ratio and strengthen the firms' integration abilities. Horizontal merge, which aims at increasing the control power of the market price and profit through the enhancement of market power, is one way to realize horizontal expanding; horizontal alliance is another way, typically the cooperation in price. The existence of asymmetry and incomplete information in reality together with the Prisoners' dilemma makes the horizontal expanding depending on cooperation always hard to sustain. Different with horizontal expanding, vertical expanding related to the merge or recompose of upstream and downstream firms in the chain. The inevitable results of vertical expanding is vertical integration, on one side, it brings the firm with competitive advantages in the horizontal level of the chain; on the other, it can reduce the risks of uncertainties and transaction costs in the industries with greater demand fluctuations ${ }^{[4]}$. Integrated expanding is composed of horizontal expanding and vertical expanding, which in essence is the integration of the firms whose products are highly linked and serves to the same or similar targets, to form the enterprise groups with international competitive power and advantages of scale economy. The merge of several firms to strengthen the integration ability pertains to the horizontal expanding, while the extension of upstream and downstream firms in the chain attributes to the vertical expanding.

\section{The influencing mechanism of industrial chain expanding to firms' independent innovation ability}

\subsection{The influencing factors of firms' independent innovation ability}

The independent innovation ability is the ability a certain firm use to developing new products or service with its own resources. It is this independent $\mathrm{R} \& \mathrm{D}$ ability that brings firm with technological breakthroughs and realizes commercialization and industrialization of products to gain more profits. Related works points out that the influencing factors focuses on firms' own condition, including technical and industrial conditions.

Such objective factors as firm's scope, management concepts, financial strengths and technological accumulations all affect firm's independent innovation ability, and these factors are also the condition and basis for the cultivation of independent innovation ability ${ }^{[5]}$. To achieve independent innovation, firms need sufficient financial and technological support, which is inseparable to the scope of firm, the management concepts determines the firms whether could judge the innovative risks and choose the right innovation form or not. Technology spillover also influences the independent 
innovation ability. Technology spillover is the technological diffuse results from the non-exclusive attribute of technology. Although patent could reduce the spillover to some extent, the public good attribute of technology always lead the successful technology innovation could be mastered by other firms with very low costs, which decrease the initiative of firms' cultivation of independent innovation ability. Risks in technology, finance and market restrain firms' independent innovation ability too. The uncertainties result in the uncertainties of innovative period, characteristics of new technology and the return of innovation. The great amount of capital in use for innovation also hinders the realization of independent innovation. Imitation innovation is another factor that influences innovation. For a long time, the feeble independent innovation ability makes the international competitiveness of industries in China weakened substantially, from this aspect, it is necessary for firms to pursue the imitation innovation mechanism before the cultivation of independent innovation ability. The life cycle of firms is greatly related to their independent innovation ability. In different stages as start-up, growth, maturity and decline, the changing internal and external conditions of firms call firms strategies to change to fit for the condition.

\subsection{The vertical integration industrial chain and its effects to independent innovation ability}

Vertical integration is the inevitable result of vertical expanding of industrial chain. This kind of $R \& D$, manufacturing and marketing operation mechanism is adopted widely by firms in the developed countries, because it can boost technology transformation, prevent technology spillover, reduce transaction costs and weaken innovation risks, which would influence the independent innovation ability.

(1) Integrated industrial chain could accelerate the transformation rate of technology and cut down the cycle of value chain. The mechanism of integration could avoid the conflicts between upstream and downstream firms caused by interest allocation, and the $R \& D$ section could serve the production line and customers directly when there is problems happens in product design process, or technological and quality problems arise. The rapid industrialization of innovation result could also reduce the technology spillover efficiently.

(2) Vertical expanding of industrial chain efficiently reduces the transaction costs from R\&D achievements to products, which provides the independent innovation process with solid financial preparation. The operation mechanism pursued by integration could conduct and maneuver resources and strength of different sections directly to reduce the transaction costs between different parts of the industrial chain and shorten the transaction cycles. Vertical integration makes the innovation and production processes coordinate with each other more closely, lowers risks and makes the independent innovation ability guide the production process more powerfully. Such characteristics of firms' independent R\&D as higher input, longer cycle, higher risk, call those firms with greater production and financial capacity to take part in independent innovation to reduce the risks in operation and management.

\subsection{The cultivation effect of imitation innovation to independent innovation ability}

The horizontal expanding of industrial chain, which depends on the merge or cooperation of firms in the same part of the chain, makes full use of their complementary resources to strengthen the core competitiveness and innovative abilities. When a firm uses a certain new technology, other could imitate this technology by their horizontal relations to realize knowledge flow and share of innovation resources. The expanding of industrial chain also decreases the diffuse costs of knowledge makes the diffuse of experience and knowledge possible.

Imitation innovation is kind of gradual innovation behavior which calls for sufficient $R \& D$ strengths to evaluate, design and improve the assimilated technology or products to create products or service more competitive and fits for the customers' demands. The cultivation effect of imitation innovation to firms' independent innovation ability is reflected by its enhancement to the knowledge and technology diffuse between firms, accelerate the accumulation of technology $\mathrm{R} \& \mathrm{D}$ and reduce the costs and risks in independent innovation to a large and possible extent.

\subsection{The extension of firm's life cycle and independent innovation}

The improvement of firms' core competitiveness and enlargement of firms' scale caused by the expanding of industrial chain not only extends the life cycle of firms, affects the intrinsic structure of industrial chain, updates the division of labor, but also extends the market scope and optimizes the industrial structure. The integration process of chain could introduce some firms with competitive advantages to the industry and force the less competitive firms to choose a certain part to reconstruct its advantages. It also helps realize the accumulation of technological experience and human resources and guarantees the cultivation of independent innovation ability.

\section{Measures and suggestions for firms in Liaoning Province to promote independent innovation abilities}

Because of their low level in the industrial chain, firms in Liaoning Province give priority to the rough machining of raw materials in steel, machinery and building materials industries, which were restricted by the varieties and distributions of the mineral resources, and with short and narrow industrial chain. The unreasonable internal structure, low level of division and lack of organic contacts all restricts the cultivation of Liaoning's firms' independent innovation ability. According to the analysis and study above, the governments in Liaoning should take some measures 
to expand the chain of different industries to enhance the cultivation of firms' independent innovation ability.

(1) Such public institutions as governments and guilds should coordinate between firms to provide them with well external environment to expand the industrial chain. In the expanding process, the government could aid firms to get through the channels that connect different firms in the chain, construct efficient factor markets and unblocked logistics networks to realize the diffuse of knowledge and share of innovation resources to cultivate firms' independent innovation ability.

(2) Governments should try their best to reduce the obstacles and unstable factors that disturb the exchange between firms. Governments could increase the financial assistance to the firms because the most influential obstacle for firms in their independent innovation ability is financial restriction. Governments could fund on independent innovation to provide firms with reliable guarantees.

(3) Governments pay more attention to the development of modern logistics industry and build platforms for the industrial chain. The governments should assist and guide the formation of logistics firms and provide the key sections with capital helps to integrate and optimize the supply chain of physical distributions. Integrate the transaction relationships between upstream and downstream firms together based on the value chain.

(4) In the cultivation process, the key link is to attract the industries with high added value. The lack of key techniques is also a bottleneck problem that restricts the development of Liaoning's firms. So the governments should breed large enterprise groups, assist and subsidy them to construct and acquire core capacity. They should formulate some favorable policies to facilitate and attract international investors to transfer the high-end sections into Liaoning's industrial chain to enhance the innovation ability of industrial chain and help cultivating the firms' independent innovation ability.

\section{Conclusion}

In this paper, we introduced the definition and patterns of industrial chain, and studied different aspects that industrial chain expanding influences independent innovation. After the analysis of problems of firms in Liaoning facing in independent innovation, we put forward the measures that governments and firms could take to enhance the independent innovation ability by industrial chain expanding. The measure we proposed here to promote independent innovation ability through industrial chain expanding is only a theoretical analysis, so future studies should set more emphasis on the empirical studies to improve firms' independent innovation ability.

\section{References}

Bettina Von Stamm.(2004). The Innovation Wave: Meeting the Corporate Challenge. Wiley: Chichester

Wang, Yiming \& Wang, Jun. (2005). Issues about the improvement of enterprise independent innovation ability. China Soft Science, 7,10-14

Liu, Gang. (2005). Structure of Knowledge Transitions and Innovations Based on an Industrial Chain. Business Economics and Administration, 11,13-17

Masten, Scott E., Meehan, James W Jr, and Snyder, Edward A. (1989). Vertical integration in the U.S. auto industry: A note on the influence of transaction specific assets." Journal of Economic Behavior and Organization, 12, 2,265-273

Li, Yuan, Li, Xiyao \& Fang, Runsheng. (2007). Analysis on the Internal Factors of Endogenous Innovation in Chinese Enterprises. Group Technology and Production Modernization, 1,9-12 